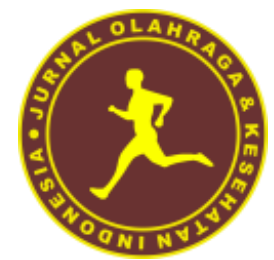

\title{
KORELASI KEKUATAN OTOT LENGAN DAN OTOT TUNGKAI DENGAN KECEPATAN ATLET RENANG
}

\author{
Harija Sembiring ${ }^{1} *$, Ibrahim Wiyaka ${ }^{2}$ \\ ${ }^{12}$ Universitas Negeri Medan, Sumatera Utara, Indonesia, 20221 \\ *Coressponding Author: rizhasembiring@gmail.com
}

\begin{tabular}{|c|c|}
\hline Keterangan & Abstrak \\
\hline $\begin{array}{l}\text { Rekam Jejak: } \\
\text { Received, April } 2021 \\
\text { Revised, Mei } 2021 \\
\text { Accepted, Juni } 2021\end{array}$ & $\begin{array}{l}\text { Renang merupakan suatu akivitas yang membutuhkan gerakan yang kompleks. } \\
\text { Agar dapat melakukan gerakan renang dengan baik dibutuhkan kemampuan untuk } \\
\text { mengkoordinasi gerakan tangan dan tungkai serta pernapasan secara harmonis. } \\
\text { Setelah kondisi fisik dalam cabang olahraga renang penguasaan teknik merupakan }\end{array}$ \\
\hline $\begin{array}{l}\text { Kata Kunci: } \\
\text { Kekuatan, Otot Lengan, } \\
\text { Otot Tungkai, Kecepatan, } \\
\text { Atlet, Renang }\end{array}$ & $\begin{array}{l}\text { hubungan antara kekuatan otot lengan dan kekuatan otot tungkai dengan hasil } \\
\text { renang gaya bebas } 50 \text { meter pada atlet putra usia } 15-17 \text { tahun Club Tirta Prima } \\
\text { Medan Tahun } 2020 \text {. Metode penelitian yang digunakan adalah metode korelasi } \\
\text { dengan uji normalitas, lineritas, korelasi sederhana dan korelasi ganda. Populasi } \\
\text { penelitian ini adalah atlet club Tirta Prima Medan Tahun } 2020 \text { sejumlah } 30 \text { atlet. }\end{array}$ \\
\hline & $\begin{array}{l}\text { Dan sampel dalam penelitian ini sejumlah } 8 \text { atlet yang ditetapkan dengan teknik } \\
\text { purposive sampling. Hasil dari penelitian ini adalah 1) Tidak ada hubungan yang } \\
\text { signifikan antara kekuatan otot lengan dengan hasil renang gaya bebas pada atlet } \\
\text { putra usia } 15-17 \text { tahun Club Tirta Prima Medan. 2) Tidak ada hubungan yang } \\
\text { signifikan antara kekuatan otot tungkai dengan hasil renang gaya bebas pada pada } \\
\text { atlet putra usia } 15-17 \text { tahun Club Tirta Prima Medan. 3) Tidak ada hubungan yang } \\
\text { signifikan antara kekuatan otot lengan dan kekuatan otot tungkai dengan hasil } \\
\text { renang gaya bebas pada atlet putra usia } 15-17 \text { tahun Club Tirta Prima Medan. }\end{array}$ \\
\hline
\end{tabular}

Copyright (C) 2020

Jurnal Olahraga \& Kesehatan Indonesia 


\section{PENDAHULUAN}

Renang merupakan suatu akivitas yang membutuhkan gerakan yang kompleks. Agar dapat melakukan gerakan renang dengan baik dibutuhkan kemampuan untuk mengkoordinasi gerakan tangan dan tungkai serta pernapasan secara harmonis.Setelah kondisi fisik dalam cabang oalahraga renang penguasaan teknik merupakan hal yang sangat penting dalam menunjang prestasi renang khususnya renang gaya bebas hal tersebut senada dengan Kurnia dan Murni (1991:10) yang mengatakan bahwa "Olahraga renang tidak hanya mengandalkan pada kondisi fisik seseorang tetapi harus memperhatikan teknik dasar renang, mengapung, meluncur, gerak nafas, gerakan kaki, gerakan lengan dan koordinasi gerak. Renang termasuk olahraga individu yang berlangsung di air atau kolam renang dengan ukuran standar internasional yaitu mempunyai panjang 50 meter dan lebar 25 meter serta kedalaman 3 meter. Dalam renang gaya bebas gerakan maju ke depan sebagian besar di tentukan oleh gerakan lengan, sedangkan gerakan kaki terutama berfungsi sebagai alat keseimbangan dan alat untuk menjaga agar kaki tetap tinggi dan memperoleh posisi mendatar (Sukintoko, 1983:91). Dari pendapat tersebut dapat disimpulkan bahwa gerakan lengan sangat mempengaruhi kecepatan renang gaya bebas.Untuk menghasilkan gerakan lengan yang maksimal seorang perenang harus menguasai teknik kayuhan lengan yang baik dan benar. Muhammad Murni (2000:27) mengemukakan bahwa "Rotasi tangan gaya bebas dibagi menjadi beberapa fase yaitu : fase masuk permukaan air (entry phase),fase menangkap (catch phase), fase menarik (pull phase), fase mendorong (push phase)dan fase istirahat (recovery phase)".

Club Tirta Prima Medan merupakan salah satu Club renang di Sumatera Utara yang sudah turut bersaing dalam kejuaraan-kejuaraan. Club ini dibentuk pada tanggal 5 agustus 2004, beralamat di kolam renang Selayang Jalan Dr.Mansyur. Club ini di pimpin oleh Primadewi Poernomo.Club tersebut telah banyak mengikuti event-event baik di kota Medan maupun yang di gelar diluar daerah yang ada di Sumatera Utara. Setelah peneliti melakukan wawancara dengan Koordinator pelatih $c l u b$ ini, ternyata $c l u b$ ini memiliki sekolah renang untuk anakanak yang usianya rata-rata dibawah 10 tahun. Dimana latihan dilakukan 2 kali dalam 1 minggu. Tujuan dari klub renang itu bukan hanya untuk melatih anak-anak bisa berenang saja melainkan juga sebagai pembibitan atlet masa depan club Tirta Prima. Oleh karena itu, setelah murid sekolah tersebut sudah dapat berenang dengan cukup baik akan dipindahkan ke club untuk dibina menjadi atlet dengan latihan yang lebih intensif yaitu selama 4 kali dalam seminggu yang terdiri dari beberapa kelompok sesuai dengan tingkatan kemampuan berenang masing-masing., menurut peneliti proses latihan yang dilakukan club tersebut terstruktur dengan baik. Namun walaupun demikian bukan berarti club tersebut tidak mempunyai masalah. Sebab pada waktu seleksi Kejurnas Renang Antar Propinsi Sumut (KRAPSU) tidak satupun atlet putera mereka yang mampu menembus limit waktu gaya bebas 50 meter yang dipatokkan oleh Pengda PRSI Sumut sebagai syarat untuk lolos kejurnas.

Berdasarkan informasi yang saya peroleh dari salah satu pelatih $c l u b$ itu yang bernama Bapak Yusrin, limit waktu gaya bebas 50 meter putera yang ditentukan untuk lolos pada event nasional itu antara lain :

- Kelompok Umur (KU IV usia 10 tahun ke bawah) limit waktunya 34,34 detik.

- Kelompok Umur (KU III usia 11-12 tahun) limit waktunya 29,64 detik.

- Kelompok Umur (KU II usia 13-14 tahun) limit waktunya 27,97 detik.

- Kelompok Umur (KU I usia 15-17 tahun) limit waktunya 26,31 detik

Dari empat limit waktu di atas, club Tirta Prima lebih mengharapkan kelompok umur I dan II untuk dapat menembus limit waktu itu, karena pada kelompok umur ini para atlet putera mereka seluruhnya sudah menguasai teknik gaya bebas dengan baik. Peneliti mencoba mencari penyebabnya sehingga peneliti berdialog tentang program latihan yang diterapkan oleh pelatih. Banyak sistem dan bentuk latihan khusus dalam olahraga renang yang di terapkan di $c l u b$ Tirta Prima Medan baik berupa latihan fisik maupun teknik. Latihan teknik seperti : latihan jarak jauh 
(distance training), latihan sprint, repetisi training, dan latihan interval jarak pendek dan jauh sedangkan untuk latihan fisik seperti : push up,sit up, knee tuck jump bahkan dengan menggunakan alat seperti tricep extention, dumbbel arm swingl, pedle swim dan lain-lain. Peralatan tersebut merupakan peralatan yang di gunakan oleh para perenang untuk latihan beberapa macam materi program latihan seperti teknik renang pada lengan, tungkai, maupun kombinasi dari kesemuanya. Akan tetapi untuk kelompok umur 15-17 tahun, pelatih memberikan latihan pada bentuk teknik. Kemudian untuk lebih mempertegas dugaan tersebut peneliti melakukan tes pendahuluan berupa tes kecepatan renang gaya bebas pada atlet putra usia 15-17tahun.

Berdasarkan hasil observasi yang dilakukan pada kegiatan latihan para atlet club Tirta Prima Medan,peneliti melihat bahwa hasil kecepatan renang gaya bebas masih lemah dan kurang maksimal.Ini dibuktikan dengan hasil tes awal yang dilakukan selama 2 kali latihan. Dalam hal ini, peneliti melakukan tes kecepatan renang gaya bebas 50 meter yang mampu dilakukan oleh para atlet masih tergolong lemah dan lambat.

Tabel 1: Hasil Observasi

\begin{tabular}{ccc}
\hline No. & Nama Atlet & Waktu(detik) \\
1 & Azis Aldiansyah & $00,41,61$ \\
2 & M. Raffy & $00,36,69$ \\
3 & Bernanda Prayuga & $00,40,86$ \\
4 & M. Hairul & $00,43,84$ \\
5 & M. Iban & $00,39,98$ \\
6 & M. Rifky & $00,39,84$ \\
7 & Aganta Sembiring & $00,38,33$ \\
8 & Pedro Hizrian & $00,37,97$ \\
\hline
\end{tabular}

Anggota struktur tubuh yang baik yakni menyangkut tentang kekuatan otot tungkai dan kekuatan otot lengan adalah merupakan salah satu potensi yang baik untuk mendapatkan kecepatan dalam renang. Oleh karena itu, orang yang mempunyai kekuatan otot tungkai dan kekuatan otot lengan rata- rata memiliki kemampuan fisik yang baik seperi kekuatan, kecepatan, daya tahan dan lain-lain. Dengan demikian untuk memperjelas latar belakang di atas maka penulis ingin melakukan suatu penelitian tentang "Hubungan Antara Kekuatan Otot Lengan dan Kekuatan Otot Tungkai dengan Hasil Renang Gaya Bebas 50 Meter Pada Atlet Putra Usia 1517 Tahun Club Tirta Prima Medan Tahun 2020”.

\section{METODE}

Penelitian lapangan yang berupa tes dan pengukuran akandilaksanakan di kolam renang selayang Jl. dr. Mansyur No.71 D Medan. Kolam ini digunakan sebagai lokasi penelitian ini karena letaknya strategis, sarana dan prasarana mendukung untuk melakukan penelitian ini dan kolam sudah memenuhi standard. Penelitian ini dilaksanakan pada hari/tanggal: Kamis, 15Oktober-2020, penelitian ini dimulai pukul 15.00 WIB sampai dengan selesai, penelitian ini dilaksanakan di kolam renang selayang Jl. Dr Mansyur No.71 Medan. Populasi adalah keseluruhan subjek peneletian (Suharsimi Arikunto, 2002:108). Salah satu sifat populasi di dalam suatu penelitian haruslah homogen.Menurut (Suharsimi Arikunto, 2002:110), apabila subjek populasi tidak homogeny,maka kesimpulan penelitian tidak boleh diberlakukan bagi seluruh populasi. Keseluruhan populasi tersebut paling sedikit mempunyai sifat yang sama.Adapun sifat yang sama yang dimaksud dalam penelitian ini yaitu seluruh atlet putra club Tirta Prima Medan yang berjumlah 45 orang. Sampel yang digunakan dalam penelitian ini adalah random sampling, Sudjana, (2002:165) menyatakan bahwa sampel adalah "Sebagian keseluruhan objek yang menjadi populasi yang dianggap dapat mewakili seluruh populasi. Pemilihan sampel dilakukan dengan random sampling, yaitu dengan sistem acak, sehingga didapat atlet yang menjadi sampel berjumlah 8 orang sampel. 
Penelitian ilmiah yang digunakan sebagai metodologi penelitian harus tepat dan mengarah pada tujuan penelitian, sehingga penelitian memperoleh hasil yang sesuai dengan tujuan penelitian. Metode penelitian adalah syarat mutlak dalam suatu penelitian, berbobot atau tidaknya mutu penelitian tergantung pada pertanggung jawaban metodologi penelitian, maka diharapkan dalam penggunaan metodologi penelitian harus tepat dan mengarah pada tujuan penelitian. Menurut Arikunto (1997:136), bahwa metodologi penelitian adalah cara yang digunakan oleh peneliti dalam mengumpulkan data penelitian. Sehubungan dengan hal tersebut, maka peneliti menggunakan metode yang dianggap sesuai dengan permasalahan yang hendak diteliti dan untuk menemukan informasi yang dibutuhkan dalam penelitian ini, dipergunakan metode penelitian tes dan pengukurandengan jenis penelitian korelasional yang bertujuan untuk menyelediki sejauh mana hubungan pada satu atau lebih faktor lain berdasarkan koefisien korelasi yang dibantu dengan teknik: (1) Observasi; (2) Dokumentasi; (3) Studi Kepustakaan; (4) Tes dan Pengukuran dan (5) Analisis data dengan teknik statistik. Sesuai dengan konsep dan judul penelitian ini, yaitu untuk mencari hubungan variabel bebas (kekuatan otot tungkai, dan kekuatan otot lengan) dengan variabel terikat (hasil renang gaya bebas).Penelitian yang digunakan yaitu desain korelasional (corelational design) yang menyatakan hubungan kekuatan otot tungkai $\left(\mathrm{X}_{1}\right)$ dan kekuatan otot lengan $\left(\mathrm{X}_{2}\right)$ dengan hasil renang gaya bebas $(\mathrm{Y})$. Adapun desain penelitian yang dimaksud terlihat pada gambar berikut :

Instrumen penelitian adalah alat atau fasilitas yang digunakan oleh peneliti dalam mengumpulkan data agar pekerjaannya lebih mudah diolah (Arikunto, 1997:160). Sesuai dengan metode penelitian yang akan digunakan dalam penelitian ini yaitu metode survey dengan teknik tes dan pengukuran, maka instrument tes yang digunakan dalam penelitian ini adalah:

- Tes Kekuatan Otot Lengan

- Nama instrumen: Push and Pull Dynamometer dari Wahjoedi (2001: 60,78)

- Tujuan: Mengukur kekuatan otot lengan.

- Tes Kekuatan Otot Tungkai

- Nama Instrumen: Leg Dynamometer

- Tujuan: Mengukur kekuatan otot tungkai

- Tes Kecepatan Renang Gaya Bebas

- Nama Instrumen: Renang gaya bebas

- Tujuan: Mengukur kecepatan renang gaya bebas

Teknik analisis data menggunakan korelasi Person Product moment. Mencari koefisien korelasi antara variabel $\mathrm{X}$ dan $\mathrm{Y}$ dapat dicari dengan rumus sebagai berikut:

$$
r_{x y}=\frac{n \sum x y-\left(\sum x\right)\left(\sum y\right)}{\left.\sqrt{\left(n \sum x\right.} 2-\left(\sum x\right)^{2}\right)\left(n \sum_{y} 2-\left(\sum y\right)^{2}\right)}
$$

Keterangan :

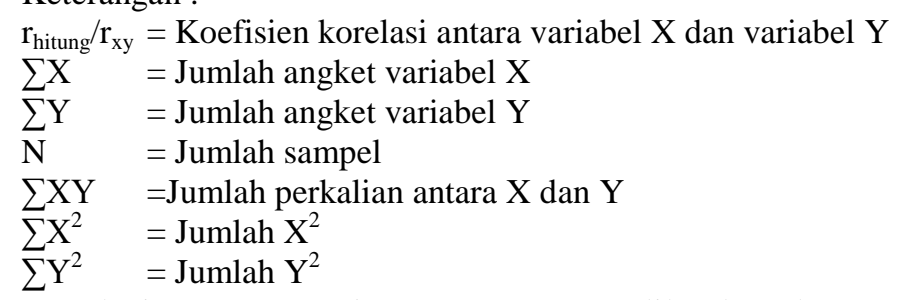

Korelasi Person Product Moment yang dilambangkan (r) dengan ketentuan nilai tidak lebih dari harga $(-1 \leq \mathrm{r} \leq+1)$. Apabila nilai $\mathrm{r}=-1$ artinya korelasi negatif sempurna; $\mathrm{r}=0$ artinya tidak ada korelasi; $r=1$ berarti korelasi sangat kuat. Sedangkan arti harga $r$ akan dikonsultasikan dengan tabel interpretasi nilai $r$ sebagai berikut: 
Tabel 2: Interpretasi Nilai $\mathrm{r}$

\begin{tabular}{cc}
\hline Nilai $r$ & Interpretasi \\
$0,80-1,000$ & Sangat Kuat \\
$0,60-0,799$ & Kuat \\
$0,40-0,599$ & Cukup Kuat \\
$0,20-0,399$ & Rendah \\
$0,00-0,199$ & Sangat Rendah \\
\hline \multicolumn{2}{r}{ (Sugiyono, 1995) }
\end{tabular}

Selanjutnya, untuk menguji signifikansi korelasi product moment dapat dilakukan dengan 2 cara, yaitu:

- Membandingkan nilai $\mathrm{r}_{\text {hitung }}$ product moment dengan $\mathrm{n}$ adalah jumlah responden dan taraf signifikan $1 \%$ atau 5\%. Kriteria uji signifikansinya adalah terima $\mathrm{H}_{\mathrm{o}}$ dantolakH $\mathrm{H}_{1} \mathrm{jikar}_{\text {hitung }} \leq \mathrm{r}_{\text {tabel }}$, sebaliknyatolakH $\mathrm{H}_{\mathrm{o}}$ danterimaH $\mathrm{H}_{1} \mathrm{jikar}_{\text {hiutng }}>\mathrm{r}_{\text {tabel }}$.

- Menggunakan rumus uji signifikansi korelasi product moment dengandk=n-2dan taraf signifikansi $1 \%$ atau $5 \%$. Kriteria uji signikansinya adalah terima $\mathrm{H}_{\mathrm{o}}$ dan tolak $\mathrm{H}_{1}$ jika $\mathrm{t}_{\text {hitung }} \leq \mathrm{t}_{\text {tabel }}$, sebaliknya tolak $\mathrm{H}_{\mathrm{o}}$ dan terima $\mathrm{H}_{1}$ jika $\mathrm{t}_{\text {hitung }}>\mathrm{t}_{\text {tabel }}$.

Dari 2 cara untuk menguji signifikansi di atas, penulis mengambil keputusan dengan mengambil cara nomor 1.Analisis korelasi berganda untuk menguji hipotesis ke-3 yaitu apakah ada atau tidaknya hubungan yang signifikan secara simultan antara kekuatan otot tungkai $\left(\mathrm{X}_{1}\right)$ dan kekuatan otot lengan $\left(\mathrm{X}_{2}\right)$ dengan hasil renang gaya bebas $(\mathrm{Y})$, dengan rumus korelasi ganda sebagai berikut :

Keterangan :

$$
\mathrm{Rx}_{1} \mathrm{x}_{2} \mathrm{y}=\frac{\sqrt{\mathrm{r}} \mathrm{r}^{\wedge} 2 \mathrm{x}_{-} 1 \mathrm{y}+\mathrm{r}^{\wedge} 2 \mathrm{x}_{-} 2 \mathrm{y}-2\left(\mathrm{rx}_{-} 1 \mathrm{y}\right)\left(\mathrm{rx}_{-} 2 \mathrm{y}\right)\left(\mathrm{rx}_{-} 1 \mathrm{x}_{-} 2\right)}{1-\mathrm{r}^{2} \mathrm{x}_{1 \mathrm{x}_{2}}}
$$

$\mathrm{Rx}_{1} \mathrm{X}_{2} \mathrm{Y}=$ Korelasi antara $\mathrm{X} 1$ dan $\mathrm{X} 2$ bersama dengan $\mathrm{Y}$

$\mathrm{rx}_{1} \mathrm{y}=$ Korelasi product moment $\mathrm{X} 1$ dengan $\mathrm{Y}$

$\mathrm{rx}_{2} \mathrm{y}=$ Korelasi product moment $\mathrm{X} 2$ dengan $\mathrm{Y}$

$\mathrm{rx}_{1} \mathrm{X}_{2}=$ Korelasi product moment $\mathrm{X} 1$ denganX2

Selanjutnya untuk mengetahui signifikan korelasi berganda terlebih dahulu $F_{\text {hitung }}$ kemudian dibandingkan dengan $\mathrm{F}_{\text {tabel }}$.

Keterangan :

$$
\text { Fhitung }=\frac{\mathrm{R}^{\wedge} 2 / \mathrm{k}}{\left(1-\mathrm{R}^{2}\right) \mathrm{n}-\mathrm{K}-1}
$$

$$
\begin{array}{ll}
\mathrm{R}^{2} & =\text { Koefisien korelasi ganda } \\
\mathrm{K} & =\text { Jumlah variabelbebas } \\
\mathrm{n} & =\text { Jumalah sampel } \\
\mathrm{F}_{\text {hitung }} & =\text { Nilai F yang dihitung }
\end{array}
$$

Kaidah pengujian signifikansi: Jika $F_{\text {hitung }} \geq F_{\text {tabel }}$, maka tolak $H_{0}$ artinya signifikan dan $F_{\text {hitung }} \leq F_{\text {tabel }}$, terima $\mathrm{H}_{\mathrm{o}}$ artinya tidak signifikan.Carilah nilai $\mathrm{F}_{\text {tabel }}$ menggunakan Tabel $\mathrm{F}$ dengan rumus:

Taraf signifikan: $\alpha=0,05$

$\mathrm{F}_{\text {tabel }}=\mathrm{F}\{(1-\alpha)(\mathrm{dk}=\mathrm{k}) /(\mathrm{dk}=\mathrm{n}-\mathrm{k}-1)\}$

\section{HASIL \& PEMBAHASAN}

\section{Hasil}

Dalam penelitian ini data yang dimaksud adalah data yang diperoleh dengan menggunakan metode korelasional dengan teknik tes dan pengukuran pada masing-masing variabel. Variabel bebas adalah kekuatan otot lengan dan kekuatan otot tungkai sedangkan varibel terikat adalah kecepatan renang gaya bebas. Sampel dalam penelitian ini adalah Atlet 
Putra Usia 15-17 Tahun Club Tirta Prima Medan Tahun 2020. Berikut tabel gambaran umum penelitian:

Tabel 3: Gambaran Umum Data Penelitian

\begin{tabular}{cccccc}
\hline & N & Minimum & Maximum & Mean & Std. Deviation \\
Kekuatan_Otot_Lengan & 8 & 22.00 & 42.00 & 31.6250 & 8.08769 \\
Kekuatan_Otot_Tungkai & 8 & 56.50 & 89.50 & 73.6875 & 12.67432 \\
Hasil_Renang_Gaya_Bebas & 8 & 36.33 & 42.98 & 39.2200 & 2.20192 \\
T_Kekuatan_Lengan & 8 & 38.10 & 62.83 & 50.0000 & 10.00000 \\
T_Kekuatan_Tungkai & 8 & 36.44 & 62.48 & 50.0000 & 10.00000 \\
T_Hasil_Renang & 8 & 36.88 & 67.08 & 50.0000 & 10.00000 \\
\hline
\end{tabular}

Dari tabel diatas dapat diketahui bahwa hasil Kekuatan Otot Lengan didapat nilai terendah 22.00, nilai tertinggi 42.00 dengan rata-rata 31.62 dan standar deviasi 8.08. Hasil Kekuatan Otot Tungkai dengan nilai terendah 56.50, nilai tertinggi 89.50 dengan rata-rata 73.68 dan standar deviasi 12.67. Dan hasil dari Renang Gaya Bebas dengan nilai terendah 36.33 nilai tertinggi 42.98 dengan nilai rata-rata 39.22 dan standar deviasi 2.20 .

Uji persyaratan analisis yang meliputi uji normalitas dan uji linearitas. Penggunaan uji normalitas untuk mengetahui normal dan tidaknya distribusi data yang diperoleh, sedangkan penggunaan uji linearitas untuk mengetahui sifat hubungannya linear atau tidak antara variabel bebas dan terikat. Hasil uji prasyarat analisis disajikan sebagai berikut:

Uji Normalitas

Uji normalitas diujikan pada masing-masing data penelitian. Uji normalitas dalam penelitian ini menggunakan rumus Chi Kuadrat (Sutrisno Hadi, 1991:252) yaitu untuk mengetahui distribusi datanya menyimpang atautidak dari distribusi normal. Kaidah yang digunakan untuk mengetahui normal dan tidaknya suatu sebaran adalah jika sig $>0.05$ sebaran dinyatakan normal, dan jika sig< 0.05 sebaran dikatakan tidak normal. Berikut tabel hasil uji normalitas:

Tabel 4: Hasil Uji Normalitas

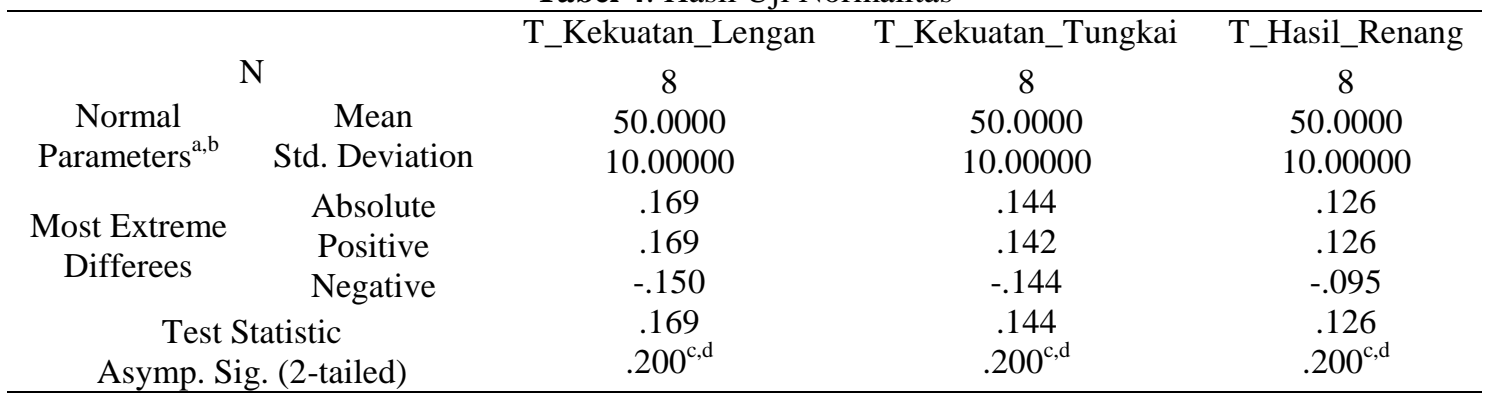

Dari tabel diatas dapat diketahui bahwa data penelitian berdistribusi normal dilihat dari semua nilai sig $>0.05$.

Uji Linieritas

Pengujian linieritas hubungan dilakukan melalui uji statistik F. Hubungan antara variabel

Kekuatan Otot Lengan (x1), variabel Kekuatan Otot Tungkai (x2), dan dengan variabel Hasil Renang Gaya Bebas (y) dinyatakan linier apabila nilai $\mathrm{F}_{\text {tabel }}>0.05$ pada taraf signifikansi $5 \%$. Hasil uji linieritas dapat dilihat dalam tabel dibawah ini: 
Tabel 5: Hasil Uji Linieritas

\begin{tabular}{ccccc}
\hline Hubungan Fungsional & Tabel & $\mathrm{d}$ & Sig. & Kesimpulan \\
$\begin{array}{c}\text { Kekuatan Otot Lengan x Hasil Renang } \\
\text { Gaya Bebas }\end{array}$ & 6.94 & $4: 2$ & 0.05 & Linier \\
$\begin{array}{c}\text { Kekuatan Otot Tungkai x Hasil Renang } \\
\text { Gaya Bebas }\end{array}$ & 6.61 & $5: 1$ & 0.05 & Linier \\
\hline
\end{tabular}

Dari tabel di atas, terlihat bahwa nilai $\mathrm{F}_{\text {tabel }}>$ signifikansi 0.05.Jadi, hubungan antara variabel bebas dan terikat pada penelitian ini dinyatakan linier.

Uji Hipotesis

Analisis data penelitian yang digunakan untuk menguj hipotesis terdiri atas analisis korelasi sederhana dan korelasi ganda.Untuk memperjelas hubungan antara variabel bebas dengna terikat maka dilakukan analisis regresi yang bertujuan untuk mengetahui persamaan regresi dan sumbangan tiap variable bebas.Uji Korelasi Variabel Bebas dengan Variabel Terikat Uji korelasi antara satu variabel bebas dengan variabel terikat menggunakan uji korelasi product moment. Uji tersebut akan digunakan untuk menguji hipotesis pertama, kedua, dan ketiga yaitu apakah ada hubungan antara satu variabel bebas dengan variabel terikat. Kriteria menerima dan menolak hipotesis yaitu membandingkan harga $r$ hitung dengan harga $r$ tabel dengan taraf signifikansi $5 \%$ atau tingkat kepercayaan $95 \%$ dan derajat bebas 10 , menerima hipotesis nihil (H0) dan menolak hipotesis alternatif (H1) apabila harga $r$ hitung kurang dari $r$ tabel. Dan menolak hipotesis nihil (H0) dan menerima hipotesis alternatif apabila harga $\mathrm{r}$ hitung lebih dari $\mathrm{r}$ tabel. Berikut tabel hasil uji hipotesis:

Tabel 6: Hasil Uji Hipotesis

\begin{tabular}{cccc}
\hline Korelasi & $\mathrm{r}_{\text {hitung }}$ & $\begin{array}{c}\mathrm{r}_{\text {tabel }} \\
(\mathrm{n}=8)\end{array}$ & Keterangan \\
$\mathrm{X} 1-\mathrm{Y}$ & -0.311 & 0.707 & Tidak Signifikan \\
$\mathrm{X} 2-\mathrm{Y}$ & 0.496 & 0.707 & Tidak Signifikan \\
\hline
\end{tabular}

Berdasarkan hasil data tabel di atas diperoleh harga $\mathrm{r}_{\text {hitung }}$ Kekuatan Otot Lengan (X1) dengan hasil renang gaya bebas $(\mathrm{Y})$ sebesar $-0,311$ sedangkan harga $r_{\text {tabel }}$ dengan taraf signifikansi sebesar 5\% sebesar 0,707. Sehingga dapat ditarik kesimpulan bahwa tidak terdapat hubungan yang signifikan antara Kekuatan Otot Lengan dengan hasil renang gaya bebas. Kemudian harga $\mathrm{r}_{\text {hitung }}$ Kekuatan Otot Tungkai (X2) dengan hasil renang gayabebas (Y) sebesar 0.496 sedangkan harga $\mathrm{r}_{\text {tabel }}$ dengan taraf signifikansi sebesar 5\% sebesar 0,707. Sehingga dapat ditarik kesimpulan bahwa tidak terdapat hubungan yang signifikan antara Kekuatan Otot Tungkai dengan hasil renang gaya bebas.

Uji Koefisien Korelasi

Kemudian hasil uji koefisien korelasi berganda. Korelasi ganda adalah hubungan antara variabel-variabel bebas bersama-sama terhadap variabel terikat. Hasil dari perhitungan korelasi ganda dengan dua variabel bebas diperoleh koefisiensi korelasi pada tabel di bawah ini:

Tabel 7: Hasil Uji Koefisien Korelasi

\begin{tabular}{ccccc}
\hline Hubungan Antar Variabel & Koefisien Korelasi & $\mathrm{F}_{\text {hitung }}$ & $\mathrm{F}_{\text {tabel }(2,5)}$ & Keterangan \\
X1.X2-Y & 0.628 & 1.626 & 5.79 & Tidak Signifikan \\
\hline
\end{tabular}

Berdasarkan tabel dapat diperoleh koefisiensi korelasi ganda antara Kekuatan otot lengan, kekuatan otot tungkai terhadap hasil renang gayabebas sebesar 0,281. Selanjutnya untuk mengetahui berarti atau tidaknya korelasi ganda terebut maka dilakukan uji $\mathrm{F}$ atau uji varians. Jadi dalam uji $\mathrm{F}$ akan menguji hipotesis apakah ada hubungan antara Kekuatan otot lengan, 
kekuatan otot tungkai secara bersama-sama terhadap hasil renang gaya bebas. Kriteria menerima dan menolak hipotesis nihil (Ho) dengan membandingkan harga $\mathrm{F}$ hitung dengan harga $\mathrm{F}$ tabel dengan taraf signifikansi (0.05) atau tingkat kepercayaan 95\% dengan derajat kebebasan v1:2, v2:5, menerima hipotesis nihil (Ho) dan menolak hipotesis alternatif (H1) apabila harga $\mathrm{F}$ hitung kurang dari $\mathrm{F}$ tabel. Dan menolak hipotesis nihil (Ho) dan menerima hipotesis alternatif (H1) apabila harga F hitung lebih dari F tabel. Dari tabel diatas diperoleh harga $\mathrm{F}$ hitung 1.626, sedangkan harga $\mathrm{F}$ tabel dengan taraf signifikansi 0,05dan derajat kebebasan v1:2, v2:5 sebesar 5.79. Harga F hitung lebih kecil dari F tabel maka H0 diterima dan Ha ditolak. Jadi dapat ditarik kesimpulan bahwa tidak terdapat hubungan antara kekuatan otot lengan dan kekuatan otot tungkai terhadap hasil renang gaya bebas.

\section{Pembahasan}

Kekuatan lengan berhubungan erat dengan kemampuan renang pada gaya bebas dengan menggunakan kekuatan dinamis karena dalam melakukan gaya tersebut perenang berusaha untuk memindahkan posisi badan dari ujung kolam ke ujung kolam. Dalam hal ini, lengan adalah alat penggerak dalam melakukan ayunan menghambat tahanan di dalam air guna membawa tubuh didalam menyikapi teknik-teknik yang ada pada gaya bebas itu sendiri. Dalam penelitian ini diketahui bahwa tidak terdapat hubungan antara kekuatanotot lengan dan kekuatan otot tungkai terhadap hasil renang gaya bebas peneliti menduga permasalahan ini disebabkan kurang baiknya kemampuan teknik renang dan rendahnya kemampuan kondisi fisik yang dimiliki siswa. Salah satunya diduga akibat kurangya siswa melatih komponen-komponen utama kondisi fisik, khususnya dalam renang gaya bebas. Untuk meningkatkan kemampuan renang dasar gaya bebas juga perlu adanya pengembangan komponen kondisi fisik, gizi, dan teknik. Karena setiap komponen penunjang tersebut saling ketergantungan. Kekuatan memang salah satu pendukung utama dalam melakukan olahraga renang tetapi tidak menutup kemungkinan bahwa teknik juga diperlukan untuk menunjang peningkatan prestasi olahraga renang teknik dasar dari setiap gerakan.Berdasarkan pendapat tersebut dapat dijelaskan bahwa teknik dalam olahraga renang perlu adanya kesempurnaan sehingga dapat menentukan gerakan keseluruhan yang baik. Kurangnya koordinasi antara gerakan lengan dan kaki serta pernapasan juga menjadi salah satu penghambat dari hasil kemampuan renang gaya bebas yang baik. Kemampuan lengan atlet dalam melakukan gerakan hentakan kurang optimal, jika lengan kurang memiliki kemampuan fisik seperti kekuatan maka kemampuan dalam melakukan gerakan-gerakan yang baik tidak akan tercapai.

Adapun beberapa faktor yang menyebabkan hasil renang gaya bebas tidak terlalu baik adalah pada saat melakukan teknik renang gaya bebas tersebut salah satunya terbatasnya waktu bagi atlet dalam melakukan renang, hal ini mungkin disebabkan keadaan pendemi covid-19. Kemudian para atlet berenang hanya pada saat perlu saja, dan tidak ada melakukan latihan mandiri.Sedangkan untuk mencapai teknik yang baik dianjurkan untuk banyak melakukan latihan secara rutin dan berulang-ulang. Hal lain yang mungkin menyebabkan kurangnya kemampuan renang gaya bebas adalah pada saat melakukan teknik renang gaya bebas yaitu kurangnya keterampilan gerak atau motor educability dan percaya diri atlet. Motor educability mempunyai peranan yang penting dalam proses pembelajaran gerak, terutama pada suatu keterampilan gerak cabang olahraga, khususnya olahraga renang gaya bebas. Penyebab lain juga ditengah kondisi pendemi covid-19 ini para atlet kurang berlatih, sehingga hasil kemampuan renang gaya bebas belum cukup maksimal.

\section{SIMPULAN}

Berdasarkan hasil penelitian dan pembahasan maka kesimpulan penelitian ini adalah sebagai berikut: tidak ada hubungan yang signifikan antara kekuatan otot lengan dengan hasil renang gaya bebas pada pada atlet putra usia 15-17 tahun Club Tirta Prima Medan, tidak ada hubungan yang signifikan antara kekuatan otot tungkai dengan hasil renang gaya bebas pada pada atlet putra usia 15-17 tahun Club Tirta Prima Medan, dan tidak ada hubungan yang 
signifikan antara kekuatan otot lengan dan kekuatan otot tungkai dengan hasil renang gaya bebas pada pada atlet putra usia 15-17 tahun Club Tirta Prima Medan.

\section{DAFTAR PUSTAKA}

Arikunto, Suharsimi. (1997). Prosedur Penelitian. Jakarta: PT Rineka Cipta.

Beachle, Early. (2007). Bugar Dengan Latihan Beban. Jakarta: PT Raja Grafindo Persada.

Djoko Pekik Irianto. (2002). Dasar Kepelatihan Olahraga. Jakarta: PT Rineka Cipta

Kravitz Lens. (2001). Panduan Lengkap Bugar Total. Jakarta: PT Raja Grafindo Persada.

Mulyaningsih. (2009). Pendidikan Jasmani Olahraga dan Kesehatan. Klaten: PT Intan Pariwara.

Murni Muhammad. (2000). Renang. Jakarta: Department Pendidikan Dan Kebudayaan Direktorat Jendral Pendidikan Tinggi.

Setiadi. (2007). Konsep Dan Penulisan Riset Keperawatan. Yogyakarta: Graha Ilmu.

Setiawan, Tunggal. (2004). Renang Dasar 1. Semarang: FIK Universitas Negeri Semarang.

Sugiyono. (1995). Prosedur Penelitian. Jakarta: PT Rineka Cipta.

Sukadiyanto. (2002). Pengantar Teori Dan Metodeologi Melatih Fisik. Jakarta: PT Rineka Cipta.

Sukinto. (1983). Renang dan Metodik. Jakarta: Depdikbud.

Sutrisno Hadi. (1991). Metodologi Research. Yogyakarta: Andi Offset.

Thomas \& David. (2000). Renang Tingkat Pemula. Jakarta: PT Raja Grafindo Persada. 